\title{
MELD SCORE, STEP FORWARD TO JUSTICE OF LIVER GRAFT ALLOCATION IN BRAZIL
}

HEADINGS - Liver transplantation. Direct tissue donation. Tissues and organ procurement. Carcinoma, hepatocellular.

"The liver graft allocation depends solely on the will of the surgeon responsible to decide, through no clear or transparent rules, among all patients, which one in the waiting list will receive the organ and may start dreaming with cure and survival. Even if this decision is made without any scientific evidence."

Nowadays, the importance of reading this sentence may seem the most distant world or a rescue period that obtains an organ for transplantation, it could be defined based on a few local centers' experiences, without clinical evidence of that is the best attitude for the patient and even the feeling of political influence, socio-economic levels or other types of unfair manipulation to society. When the liver transplantation in the 80 's was transformed as a therapeutic option, the decision of who would get the organ depends on the surgeon and this was Brazil's situation until 1997, when the Brazilian National Transplantation System (SNT) and unique list was introduced.

Since then, we could count on system totally controlled by the State, the Government Department, as well as Brazilian Health Ministry that, in this case of liver transplantation, the graft allocation was considered by the blood type compatibility and patients chronological order in the waiting list, not the severity of illness index, but the waiting time.

This change showed a big evolution to SNT that established a clear and transparent criterion to graft allocation rules for those who were waiting. For the first time in this country, we as transplant surgeons, could guaranty to our patients that no one, under any situation, may interfere in the way of the organ destination by another criterion unless the described above.

Even though, with all the advantages of that this new system attributes to Brazilian transfer process, its bring others new inconvenient, for example the precocious addition of patients who suffer from liver diseases in the waiting list without an adequate indication to liver transplantation, since we have low rates of donor, the candidates for liver transplantation could wait for anecdotics 36 to 48 months to undergo the transplant. It is important to mention that, in that moment, transplant was indicated for people in high mortality risks between 12 to 18 months from diagnostic or indications for transplant.

Another discussion was on carrying about patients with more severe liver disease mortality in waiting list, since the severity of illness has no importance to decide the organ allocation. The waiting list in Brazil has increased; reaching 7,000 patients waiting for treatment, at the same time from 1997 to 2000, 221 and 482 liver transplants were performed respectively ${ }^{(1)}$.
However, this inadequacy between donor and recipient was not a Brazilian's prerogative, we were in front of a discomfort scenario and during this time the United States of America used for 10 years, the severity of illness index (UNOS -1, 2A, 2B, e 3) based on Child-Turcotte-Pugh and the need for hospital admission ${ }^{(6)}$.

For the continuous increaser of patient's death on waiting list, the USA formed the Liver Allocation Committee and, in February 2002 the MELD - Model for End-Stage Liver Disease was established for liver graft allocation in that country.

The MELD was initially developed to predict the mortality of the patients submitted to TIPS (Transjugular intrahepatic portosystemic shunt) and later on, after some changes, presented as an excellent method to predict the mortality between 3 and 12 months for those who were waiting for the transplant ${ }^{(3)}$.

Turns to Brazil, many discussions were necessary up to the adopted of MELD and PELD (Pediatric End-Stage of Liver Disease) in July 2007, also with alterations, some of them still not applied in other countries like PELD multiplication by 3 , positioning, by intelligent and just form, children ahead of adults for transplantation. Among the existent worries, was the possibility of the increase mortality rates post-transplant, since we have low rates of donor, as mentioned, we would transplant, theoretically, only patients with elevated MELD score, and consequently very ill.

Bearing the international experience, in Brazil we opted to characterize some clinical conditions as "special situations". This condition, although not affecting seriously the liver functions may develop fast into clinical worsening, up to the death, without MELD score increase. Therefore, these patients are classified in the different form, given them 20 points to be included in waiting list, enlarged for 24 and 29 points after 3 and 6 months waiting to obtain the organ, respectively.

We find the following conditions: metastatic/ unresectable neuroendocrine tumors restricted to the liver, familial amyloidotic polyneuropathy type I and II, hepatopulmonary syndrome, metabolic diseases (cystic fibrosis, glycogen storage disease type I and IV, polycystic diseases, alpha 1-antitrypsin deficiency, hepatolenticular degeneration, primary oxalosis) and the most important the hepatocellular carcinoma (HCC), inside the Milan criteria (solitary tumor $\leq 5 \mathrm{~cm}$ or three nodules of $\leq 3$ $\mathrm{cm}$ per each, without evidence of macroscopic vascular invasion and extrahepatic disease) $)^{(4)}$.

Since the introduction of this new policy, the biggest "beneficiary" was the HCC patient. According to the Secretary 
of Health of State of São Paulo - Brazil data, a State with approximately 40,000,000 of inhabitants, between July 2006 and August 2007, 388 liver transplants, $328(84.5 \%)$ in adults and $60(15.5 \%)$ in children were performed. Among the adults, 129 (33.2\%) get an extra score by special situation, $99(76.7 \%)$ of them had $\mathrm{HCC}^{(5)}$.

It is means that $30.2 \%$ of all the transplants carried out in adults during this period have hepatocellular carcinoma detected.

FREITAS at al. ${ }^{(2)}$ in this issue of ARQUIVOS de GASTROENTEROLOGIA present an index of $18.3 \%$ people with $\mathrm{HCC}$, in measure 71 transplants undergoing pre-MELD in a Liver transplant Unit at State of Paraná. Unfortunately, these data get less than $50 \%$ of the total, not considered in this publication by lack of data in medical chart to adequate analysis.

It would be important to identify, at least, the number of patients with HCC and the mortality of these excluded groups to more support of the results presented. In the same article, FREITAS et al. ${ }^{(2)}$ emphasize the significant difference between MELD in group with HCC correction detection (11 points) when compared of the group without HCC recurrence (16 points). At Secretary of Health of State of São Paulo, Brazil, the MELD cases without extra points analysed, we find $42.7 \%$ of the transplants performed up to 18 points index; this number get less to $7.2 \%$ after correction from "special situations" (extra points) that $76.7 \%$ are HCC.

The FREITAS et al. ${ }^{(2)}$ paper proves another data that the less gravity of the transplanted patients from HCC was the reduced necessity of blood transfusion in this group of patients, suggesting an inferior complex clinical-surgical. During MELD used in Brazil the number of dead donor keeps low, range of $6 \mathrm{pmp} /$ year (per million people) attending a small part of the necessary need. It is imply undergoing transplants, without special situations and higher MELD, although when we compare the survival since and after MELD adopted, the rates are keep very near in the State of São Paulo ${ }^{(5)}$.

Currently, the model MELD is based on objective variables (bilirubin, creatinine and INR) support by the most numbers of the Brazilian transplant centers, although it still needs improvement. The first experience analysis of MELD establish in Brazil, was the State of São Paulo experience, the only Transplant Center that follow and spreads the reports. From these reports we can conclude: (1). The model permit transplant critical patients, in spite of the period on waiting list; (2). the possibility to transplant $30.1 \%$ patients with MELD score higher or equal of 30; (3). the reduced of enrolled number on waiting list, withdrawing, perhaps, early enrolled; (4). the patient survival rates did not decrease when compared with the pre-MELD era; (5). established priority to pediatric transplantation (PELD multiplied by 3 ) that changing, approximately, from $10 \%$ to $16 \%$ of allocation; (6). given privileges to $\mathrm{HCC}$ cases which were approximately $3 \%$ and currently represent $39.1 \%$ the transplants; (7). remain the acute liver failure to O'Grady and Clichy criteria, and finally; (8). promoting transparency of severity of illness index.

Among factors that may influence the changes in allocation MELD scale, we should include the convenience in remain it score checked for "special situations", maybe high reaching 29 points. Patients with higher MELDs, between 24 and 28, "lose" the opportunity to transplant on behalf of many HCC patients who present conditions for waiting more time to transplant. Other aspect, not less important, refers to the use of resource that clearly presents itself very much increase after MELD establishment, under the optics of our service itself.

Although it hard to do, we cannot avoid on discuss and analyze the "justice and utility". Perhaps, more important is follow-up and the constant checking of the national results for the principle of Brazilian System of Health (SUS) can reach its basic precepts of equity in organ sharing.

We can realize clearly that the process of liver transplant in Brazil presented a fast evolution during last 10 years, start of 200 liver transplants performed per year, without criteria for graft allocation, to current of more than 1000 liver transplants per year, under objective and socially criteria of organs allocation, added up to the results follow-up and the constant discussions forwards to improvements.

Now, perhaps the most difficult changes is assist the actions that will retreat Brazil, country with great number of solid transplants performed, the less numbers of 6 effective donors to multiple organs pmp/year to be compared to developed countries, which present around 15 one.

Therefore, the MELD scale imperfections could be minimized, while the criterion is improve by transplant undergoing increase and the possibility to more people to obtain a organ, even though those who have not reached a severe clinical status, with very high MELD scores.

Ben-Hur FERRAZ-NETO*

Ferraz-Neto B-H. MELD escore, mais um passo na justiça da alocação de enxertos para transplante de fígado no Brasil. Arq Gastroenterol. 2007;44(3):187-8. DESCRITORES - Transplante de fígado. Doação dirigida de tecido. Obtenção de tecidos e órgãos. Carcinoma hepatocelular.

\section{REFERENCES}

1. Associação Brasileira de Transplante de Órgãos. [online] Registro Brasileiro de Transplantes 2006. [citado set 2007]. Available: http://www.abto.org.br/profissionais/profissionais.asp

2. Freitas AC, Parolin MB, Stadnik L, Coelho JC. Carcinoma hepatocelular: impacto do tempo em lista e das formas de tratamento pré-operatório na sobrevida do transplante de figado cadavérico na era pré-MELD em um centro no Brasil. Arq Gastroenterol. 2007;44:189-94.

3. Kamath PS, Wiesner RH, Malinchoc M, Kremers W, Therneau TM, Kosberg CL, D'Amico G, Dickson ER, Kim WR. A model to predict survival in patients with end-stage liver disease. Hepatology. 2001;33:464-70.
4. Mazzaferro V, Regalia E, Doci R, Andreola S, Pulvirenti A, Bozzetti F, Montalto F, Ammatuna M, Morabito A, Gennari L. Liver transplantation for the treatment of small hepatocellular carcinomas in patients with cirrhosis. N Engl J Med. 1996;334:693-9.

5. São Paulo. Secretaria do Estado da Saúde. [on line] Central de Transplantes [cited 2007 sept]. Available: http://ctxses.saude.sp.gov.br/IndexEquipe. aspx? totalEquipes $=4$.

6. United Network for Organ Sharing. [online] Components of the CTP score employed in the previous liver allocation policy. [cited 2007 sept]. Available from: http://www. unos.org/

\footnotetext{
* Liver Transplantation Program of Hospital Israelita Albert Einstein, São Paulo, SP, and Surgical Department of Catholic University School of Medicine, Sorocaba, SP, Brazil.
} 